\title{
DIEZ AÑOS DE LA ADOPCIÓN DE LA DECISIÓN MARCO 2008/841/JAI DEL CONSEJO RELATIVA A LA LUCHA CONTRA LA DELINCUENCIA ORGANIZADA. LUCES Y SOMBRAS DE UN LEGADO MÁS QUE DUDOSO
}

\author{
LUCAS J. RUIZ DÍAZ \\ Universidad de Granada \\ lucasruiz@ugr.es
}

Cómo citar/Citation

Ruiz Díaz, L. J. (2018).

Diez años de la adopción de la Decisión Marco 2008/841/JA

del Consejo relativa a la lucha contra la delincuencia organizada. Luces y sombras de un legado más que dudoso. Revista de Derecho Comunitario Europeo, 61, 1091-1119. doi: https://doi.org/10.18042/cepc/rdce.61.08

\section{Resumen}

Con la aprobación de la Decisión Marco 2008/841/JAI sobre la lucha contra el crimen organizado, la Unión Europea dio un paso importante en la consolidación de un marco legal propio y relativamente autónomo para atajar este fenómeno delictivo mediante el recurso al derecho penal. Sin embargo, y a pesar de los logros que se le presumen desde su publicación, la decisión marco ha dejado numerosos interrogantes debido especialmente a las lagunas del texto finalmente adoptado por el Consejo,

1 Doctor en Derecho Internacional Público y Relaciones Internacionales, Universidad de Granada. Investigador visitante en el Institute for European Studies de la Vrije Universiteit Brussel (IES, VUB). Todas las páginas web referenciadas en el presente estudio fueron consultadas por última vez el 31 de agosto de 2018. Este trabajo es una revisión y actualización de un apartado de la tesis presentada por el autor en 2015 para la obtención del título de doctor, en particular con motivo de la posterior publicación de un informe de evaluación de la Comisión sobre la presente decisión marco que ilustra el escaso éxito de su transposición al ordenamiento interno de los Estados miembros. 
así como por su dispar trasposición al ordenamiento de los Estados miembros. En particular, determinados asuntos requieren de mayor claridad, al mismo tiempo que se precisan nuevas iniciativas que suplan las deficiencias observadas en el marco comunitario y la práctica seguida por las autoridades judiciales estatales. Solamente así quedarían garantizados los principios básicos del derecho penal y aquellos sobre los que se asienta el propio espacio judicial europeo, como el reconocimiento mutuo.

\title{
Palabras clave
}

Crimen organizado transnacional; Unión Europea; derecho penal europeo; Espacio de Libertad, Seguridad y Justicia.

\section{TEN YEARS AFTER THE ADOPTION OF COUNCIL FRAMEWORK DECISION 2008/841/JHA ON THE FIGHT AGAINST ORGANISED CRIME. LIGHTS AND SHADOWS OF A DOUBTFUL LEGACY}

\begin{abstract}
The European Union took a step forward in the consolidation of its own, relatively autonomous legal framework to fight transnational organised crime with the adoption of the Council Framework Decision 2008/841/JHA on the fight against organised crime. It did so by resorting to Criminal Law as an active element of its intervention in the field. Even though there are major achievements resulting from its adoption, the Framework Decision raised some concerns as regards the considerable gaps in the text finally endorsed by the Council, as well as its uneven incorporation into Member States' domestic law. In particular, some issues call for further accuracy and new initiatives to effectively address the deficits observed both in the European legal framework and the legal practice in order to prevent from failure basic principles of national Criminal Law and those principles on which the European judicial area rely, such as mutual recognition.
\end{abstract}

\section{Keywords}

Transnational organised crime; European Union; European Criminal Law; Area of Freedom, Security and Justice.

\section{ANS APRÈS L'ADOPTION DE LA DÉCISION-CADRE 2008/841/JAI DU CONSEIL RELATIVE À LA LUTTE CONTRE LA CRIMINALITÉ ORGANISÉE. UN HÉRITAGE ENTRE L'OMBRE ET LA LUMIÈRE}

\section{Résumé}

Avec l'adoption de la Décision-cadre 2008/841/JAI du Conseil relative à la lutte contre la criminalité organisée, l'Union européenne franchit une importante 
étape en consolidant son propre cadre législatif de lutte contre la criminalité organisée, relativement autonome, en ayant recours au Droit pénal afin de soutenir son intervention. Malgré les bons résultats obtenus dans certains domaines, la Décision-cadre a soulevé de nombreuses questions, notamment en raison des déficiences du texte définitivement adopté par le Conseil, ainsi que par son asymétrique transposition en droit interne par les États membres. Plus concrètement, il faudrait que certaines questions soient précisées et il est jugé nécessaire de présenter de nouvelles initiatives visant à remédier aux déficiences du cadre légal européen et observées lors de la pratique des autorités judiciaires des États membres. Cette action est singulièrement nécessaire si l'on veut sauvegarder les principes de base du Droit pénal des États membres et les fondements mêmes de l'espace judiciaire européen, tels que la reconnaissance mutuelle.

\section{Mots clés}

Criminalité organisée transnationale; Union Européenne; Droit pénal européen; Espace de Liberté, Sécurité et Justice. 


\section{SUMARIO}

I. EL LARGO CAMINO HACIA LA ADOPCIÓN DE LA DECISIÓN MARCO. ALTAS EXPECTATIVAS, RESULTADOS LIMITADOS. II. LOS PRINCIPALES ASPECTOS DE LA DECISIÓN MARCO. DEFINICIONES, TIPIFICACIONES Y SANCIONES PREVISTAS: 1. Definiciones y elementos de referencia. 2. La tipificación de los delitos de pertenencia. 3. Sanciones. III. BALANCE DE LA DECISIÓN MARCO. ¿̇HA SUPUESTO UN CAMBIO REAL EN LA POLÍTICA CRIMINAL DE LOS ESTADOS MIEMBROS Y DE LA UNIÓN EUROPEA?: 1. Evaluación general del impacto de la decisión marco en el ordenamiento de los Estados miembros. 2. Las principales lagunas y cuestiones por resolver. IV. CONCLUSIONES. BiBLIOGRAFIA.

\section{EL LARGO CAMINO HACIA LA ADOPCIÓN DE LA DECISIÓN MARCO. ALTAS EXPECTATIVAS, RESULTADOS LIMITADOS}

La publicación de la decisión marco (DM) relativa a la lucha contra el crimen organizado transnacional $\left(\right.$ COT) ${ }^{2}$, en noviembre de 2008, culmina un largo proceso interno con una doble vertiente: por un lado, la identificación a nivel estratégico del fenómeno como amenaza a través de una serie de documentos de programación y planes de acción ${ }^{3}$; y, por otro, la traslación al ordenamiento jurídico comunitario de un concepto criminológico multiforme de difícil acomodo legal, como se ha venido advirtiendo desde la doctrina

2 Decisión Marco 2008/841/JAI del Consejo, de 24 de octubre de 2008, relativa a la lucha contra la delincuencia organizada (DO L 300, de 11 de noviembre de 2008, p. 42).

3 Aparte de los programas quinquenales de implementación del Espacio de Libertad, Seguridad y Justicia (ESLJ), específicamente contra el COT se adoptaron, entre otros documentos, el Plan de Acción para luchar contra la delincuencia organizada, adoptado por el Consejo el 28 de abril de 1997 (DO C 251, de 15 de agosto de 1997, p. 1) y la Estrategia de la Unión Europea para el comienzo del nuevo milenio (DO C 124, de 3 de mayo de 2000, p. 1). Para una panorámica general de la lucha contra el COT en la UE desde las propias instituciones, véase Multidisciplinary Group on Organized Crime 1997-2007: looking back and preparing the future, 10554/07, Bruselas, 13 de julio de 2007. 
(Mitsilegas et al., 2003; Cesoni, 2007; González Rus, 2014). En principio, la DM tenía por misión actualizar el marco legal comunitario, vigente desde $1998^{4}$, para adaptarlo a la nueva realidad de la integración europea auspiciada por el progresivo desarrollo del Espacio de Libertad, Seguridad y Justicia (ELSJ). Además, la aprobación de la Convención de Palermo 5 empujaba a la Unión Europea (UE) a actuar para corregir las limitaciones identificadas en el anterior marco normativo (Maljević, 2011; Mitsilegas, 2001). Con esta reforma, según afirmaba la propia Comisión en su propuesta, la Unión proporcionaba una herramienta "mucho más completa» y eficaz para luchar contra el COT (Comisión, 2005a: 4), en esta ocasión con carácter obligatorio, situando como referente a la decisión marco contra el terrorismo ${ }^{6}$ y asimilando —al menos, en teoría - la legislación europea a las disposiciones del marco transnacional de Naciones Unidas.

Esta DM tenía un doble objetivo. Por un lado, armonizar la diversidad normativa de los Estados miembros en relación con la tipificación de los delitos de participación en organización delictiva. Esta cuestión dificultaba enormemente la cooperación judicial y policial en el espacio europeo, puesto que algunas legislaciones nacionales exigían la comisión efectiva de un delito para incriminar penalmente a un individuo, mientras que, en determinados Estados miembros, esa norma específica sencillamente no existía. De esta forma, como se reconocía en su preámbulo, se lograría facilitar la aplicación real del principio de reconocimiento mutuo por medio de la inclusión de un estándar mínimo, común a todos los Estados miembros, que garantizara una cierta homogeneidad. Por otro lado, la DM obligaba a que los legisladores

4 Acción común 98/733/JAI, de 21 de diciembre de 1998, adoptada por el Consejo sobre la base del artículo K.3 del Tratado de la Unión Europea, relativa a la tipificación penal de la participación en una organización delictiva en los Estados miembros de la Unión Europea (DO L 351, de 29 de diciembre de 1998, p. 1).

5 Convención de Naciones Unidas contra la Delincuencia Organizada Transnacional, adoptada por Resolución 55/25 de la Asamblea General, de 15 de noviembre de 2000 (U.N.T.S., vol. 2225, p. 373). La UE se adhirió a la Convención de Palermo mediante Decisión 2004/579/CE del Consejo, de 29 de abril de 2004, relativa a la celebración, en nombre de la Comunidad Europea, de la Convención de las Naciones Unidas contra la Delincuencia Organizada Transnacional (DO L 261, de 6 de agosto de 2004, p. 69).

6 Decisión Marco 2002/475/JAI del Consejo, de 13 de junio de 2002, sobre la lucha contra el terrorismo, DO L 164, de 22 de junio de 2002, p. 3. Esta decisión marco fue reemplazada por la Directiva 2017/541 del Parlamento Europeo y del Consejo, de 15 de marzo de 2017, relativa a la lucha contra el terrorismo (DO L 88, de 31 de marzo de 2017, p. 6). 
nacionales adoptaran las sanciones «correspondientes a la gravedad de estos delitos», instaurando un umbral mínimo que, sobre el documento finalmente aprobado por el Consejo, no cumpliría con las expectativas de la propuesta promovida por la Comisión al rebajar los grados de las sanciones previstas inicialmente ${ }^{7}$.

En realidad, el documento final aprobado por el Consejo rebajaría considerablemente las expectativas suscitadas por la propuesta de la Comisión, en particular en aquellos puntos más innovadores respecto del marco anterior. En primer lugar, la DM excluye de su ámbito material ciertos delitos relacionados con el COT recogidos en la propuesta de la Comisión —e incluidos en la Convención de Palermo- que hubieran supuesto una verdadera innovación respecto del marco anterior $y$, de haberse aprobado, hubieran marcado las principales pautas para la armonización real de los diferentes sistemas penales de los Estados miembros. En la tramitación del texto se eliminaron, sin embargo, las principales novedades de la propuesta por la Comisión. Así, por ejemplo, en la DM finalmente adoptada se incluyó la tipificación del "acuerdo" (o conspiracy). Este delito, heredero del common law anglosajón, fue introducido por las presiones de ciertos Estados miembros que disponían ya de esa figura en sus respectivos ordenamientos, como el Reino Unido y Chipre, significando un "paso atrás» en la lucha contra el COT al mantener el doble esquema seguido por la Acción Común de 1998 que la Comisión había desterrado en su propuesta con el fin de simplificar el modelo europeo. Otra de las importantes novedades descartadas fue la tipificación de la «dirección de una organización delictiva», recogida tanto en el art. 2 de la propuesta como en la Convención de Palermo (art. 5.1.b) y presentada como una de las principales innovaciones de la iniciativa de la Comisión, al diferenciar los diversos grados de participación en organización delictiva y establecer las sanciones correspondientes en función de su gravedad. Por último, en la redacción inicial de su considerando número 5 y art. 8.2 se mencionaba la protección y asistencia a las víctimas de los delitos contemplados en la DM a través de medidas específicas. El Consejo, no obstante, desecharía durante las primeras etapas de las negociaciones incluir esta disposición concreta en el texto final por considerar que esta cuestión debía regularse de manera diferenciada, en

\footnotetext{
Mientras que en la propuesta de la Comisión se preveía una pena privativa de libertad máxima de al menos cinco años (grado 3), durante la tramitación del texto se rebajó la sanción a una pena máxima de reclusión de al menos entre dos y cinco años (grado 2). Sobre el establecimiento de los grados máximos de las penas que debe fijar la legislación nacional para determinados delitos, véanse las Conclusiones del Consejo sobre el enfoque que debe seguirse para la aproximación de las penas, 9141/02, de 27 de mayo de 2002.
} 
particular mediante la aplicación de la norma europea existente relativa al estatuto de la víctima en el proceso penal ${ }^{8}$. En definitiva, los cambios operados por el Consejo serían de tal envergadura que la propia Comisión se desmarcó del documento aprobado por considerar prácticamente imposible conseguir la pretendida armonización a través del texto resultante (Consejo de la Unión Europea, 2006: 12). Además de ser apoyada en su momento por Francia e Italia, años más tarde el Parlamento Europeo le daría la razón a la Comisión dado el escaso grado de armonización alcanzado con esta DM (Parlamento Europeo, 2011).

En general, pese a la escasa armonización conseguida, la DM ha proporcionado el marco jurídico necesario para afianzar el progresivo desarrollo de la política «común» contra el COT tanto a nivel operativo como estratégico (Ruiz Díaz, 2015). Este conciso texto ha representado el principal instrumento legal de referencia para la actuación de la UE en este complejo terreno, otrora reservado a las soberanías nacionales. Además, simboliza el nexo de unión entre la concepción criminológica de un fenómeno delictivo multiforme y su difícil traslación al ordenamiento comunitario. El objetivo de este estudio es analizar las principales aportaciones de la DM al marco europeo en relación con la incorporación de definiciones y la tipificación de ciertos delitos conectados con el COT, principalmente el de participación en organización delictiva. Como observaremos en los apartados que siguen, la armonización inicialmente pretendida ha sido escasa en la práctica, si bien de su transposición por el legislador nacional se han derivado otras consecuencias merecedoras de especial atención por los resultados que acarrean para el conjunto del espacio judicial europeo, como la extralimitación en la incorporación de los mínimos exigidos en algunos aspectos facultativos de la DM. Además, se expondrán las lagunas más evidentes tanto de la DM como de su implementación en los ordenamientos internos de los Estados miembros, en particular en aquellos aspectos que afectan directa o indirectamente a la aplicación efectiva del reconocimiento y la confianza mutuos sobre los que descansa el espacio judicial europeo. Por último, se apuntan brevemente las potenciales próximas etapas en la definición del marco legal contra el COT ante las opciones

8 La normativa existente en ese momento era la Decisión Marco 2001/221/JAI, de 15 de marzo de 2001, relativa al estatuto de la víctima en el proceso penal (DO L 82, de 22 de marzo de 2001, p.1), hoy derogada por la Directiva 2012/29/UE (DO L 315, de 14 de noviembre de 2012, p. 57). Nuevamente, a diferencia de la DM contra el terrorismo, que sí incluía una disposición específica de asistencia similar a la propuesta por la Comisión para el caso de las víctimas del COT, el Consejo volvería a desmarcarse y desechar esta posibilidad durante la tramitación del texto. 
apuntadas por las instituciones comunitarias y la necesidad de reformas que pongan fin a la incertidumbre jurídica agravada por la dispar implementación de esta DM.

\section{LOS PRINCIPALES ASPECTOS DE LA DECISIÓN MARCO. DEFINICIONES, TIPIFICACIONES Y SANCIONES PREVISTAS}

\section{DEFINICIONES Y ELEMENTOS DE REFERENCIA}

La DM ofrece pocas innovaciones respecto del marco penal transnacional y europeo vigente en materia de definición de los delitos a tipificar. Así, mantiene - con ligeras modificaciones - las amplias definiciones incorporadas al derecho comunitario por la Acción Común y contenidas en la Convención de Palermo, comprometiendo el alcance e impacto real de la aproximación pretendida inicialmente con la propuesta de la Comisión. En primer lugar, la DM emplea la expresión "organización delictiva»" en su articulado, a diferencia del correspondiente concepto "grupo delictivo organizado» de la Convención de Palermo, que resalta el perfil «organizado» del grupo criminal, tal y como lo ha concebido tradicionalmente la doctrina. No obstante, contrariamente al marco comunitario anterior, en la DM se especifica que el fin último de toda "organización delictiva» es la búsqueda del lucro económico «u otro beneficio de orden material» ampliamente considerado ${ }^{10}$. En consecuencia, quedan excluidos de este nuevo marco comunitario los grupos terroristas, regulados de manera diferenciada tanto a nivel internacional y transnacional como de la propia Unión ${ }^{11}$.

9 «Una asociación estructurada de más de dos personas, establecida durante un cierto período de tiempo y que actúa de manera concertada con el fin de cometer delitos sancionables con una pena privativa de libertad o una medida de seguridad privativa de libertad de un máximo de al menos cuatro años o con una pena aún más severa, con el objetivo de obtener, directa o indirectamente, un beneficio económico u otro beneficio de orden material».

10 La DM, sin embargo, no se detiene a delimitar este término, por lo que habrán de considerarse todo tipo de beneficios o ganancias atendiendo a la correspondiente aclaración de las Guías Explicativas de la Convención de Palermo (Oficina de Naciones Unidas contra la Droga y el Delito, 2004: 13).

11 Baste recordar la existencia de la Directiva 2017/541 del Parlamento Europeo y del Consejo, de 15 de marzo de 2017, relativa a la lucha contra el terrorismo, así como instrumentos anteriores (véase supra nota 6 para referencias). 
Adicionalmente, la DM exige otros elementos comunes indispensables para considerar un grupo criminal como organización delictiva: 1) pluralidad de individuos; 2) estabilidad temporal del grupo criminal; y 3) cierta estructura organizativa (Méndez Rodríguez, 2009; Maljevic, 2011). Con relación al número de integrantes, la DM mantiene que sean, como mínimo, «más de dos personas», sin innovar respecto de la Acción Común pese a las críticas recibidas desde la criminología por el bajo número de integrantes exigido por la normativa comunitaria. Asimismo, a pesar de los intentos de supresión del carácter estructural por parte de la Eurocámara (Parlamento Europeo, 2005) y en un intento por acotar el ámbito subjetivo y material de la DM, la definición del art. 1 incluye otros requisitos suplementarios con el fin de distinguir la «organización delictiva» de formas tradicionales de codelincuencia (Méndez Rodríguez, 2009: 14). Estos criterios de estructuración quedarían precisados terminológicamente, en teoría, con la definición de "asociación estructurada» incluida en el mismo art. $1^{12}$.

Un requisito adicional que se desprende de esta definición de «organización delictiva" y del elemento estructural es el necesario "concierto» de sus componentes. Para que estos delitos sean objeto del ámbito material de la DM, los miembros de una organización delictiva han de «acordar» su actividad criminal conforme a un plan, a instigación y/o bajo la dirección de uno o varios individuos. Esta sería la «delincuencia de grupo» (Choclán Montalvo, 2001) o el elemento «sistémico» de la actuación criminal (Aleo, 2002; Martin y Romano, 1992); una característica que, sin embargo, aparece difuminada en el marco comunitario al no haberse recogido finalmente los delitos de «dirección» e «instigación» en la DM aprobada por el Consejo, como inicialmente propusiera la Comisión.

Por último, se requiere la comisión de un delito grave para que la normativa comunitaria sea de aplicación. Según la lacónica definición de «organización delictiva» recogida en la DM, se entiende que será toda conducta sancionable con una pena máxima de reclusión de «al menos cuatro años o

12 «Una organización no formada fortuitamente para la comisión inmediata de un delito ni que necesite haber asignado a sus miembros funciones formalmente definidas, continuidad en la condición de miembro, o exista una estructura desarrollada». Esta definición en negativo es evidentemente amplia y ambigua, rompiendo con la necesaria claridad que precisa la legislación penal para salvaguardar los principios de legalidad y seguridad jurídica. Por ello, al afirmar que no se precisa de una estructura desarrollada formalmente para cometer sus actividades delictivas, se desmontan las tesis mantenidas por gran parte de la doctrina en el siglo $\mathrm{xx}$, principalmente desde la criminología estadounidense o influida por esta (Cressey, 1969; Finckenauer, 2005; Hagan, 2006). 
con una pena aún más severa» (art. 1). Con la incorporación de este umbral mínimo de penas, la Unión rehúye entrar en un debate baldío sobre los criterios indispensables para determinar la gravedad de los delitos que hubiera afectado al consenso necesario para adoptar la DM, si bien a costa de sacrificar cierta seguridad jurídica. La ausencia de una enumeración detallada, no obstante, ha sido suplida por las referencias continuas al listado incluido en el anexo del Convenio Europol ${ }^{13}$ y por otros instrumentos del derecho penal de la UE que, indirectamente, han acotado el fenómeno del COT al legislar específicamente sobre aspectos parciales y delitos relacionados con el mismo (por ejemplo, tráficos ilícitos, trata de seres humanos, blanqueo de capitales y productos del delito, ciberdelincuencia, etc.), en cuyo caso el delito de pertenencia a organización delictiva ha sido introducido como circunstancia agravante.

En resumen, la DM mantiene las lagunas y errores en la delimitación del COT del marco anterior, dejando excesivamente abierto el ámbito de aplicación material y personal de la DM. Especialmente, se echan en falta en las definiciones determinados elementos esenciales identificados por la criminología que no han sido tenidos en cuenta en la redacción y tramitación de la DM para delimitar el COT frente a otros tipos de criminalidad, como el uso de algún tipo de disciplina o de control por parte de la organización, la utilización de la violencia u otros medios destinados a intimidar o que sus componentes pretendan ejercer influencia sobre el medio político y económico, si bien estos elementos sí estaban incluidos como características del COT en documentos previos que han tenido cierta relevancia en el desarrollo de la política de la UE en esta materia (Consejo de la Unión Europea, 2000: 11-12; Europol, 2004; Comisión Europea, 2005b). Asimismo, es, cuando menos, llamativa la falta de mención en toda la DM al carácter transnacional del crimen organizado, germen de la intervención comunitaria, o a la corrupción como "vehículo de las actividades» del COT (Comisión Europea, 2011: 12). Sin embargo, como en el caso de otras importantes ausencias apuntadas anteriormente en cuanto a los elementos del COT, la corrupción no está presente entre los delitos a tipificar por mandato de la DM, además de otras ofensas previstas en el marco transnacional de Palermo que no fueron retenidas por el legislador europeo.

13 Anexo del Convenio basado en el artículo K.3 del Tratado de la Unión Europea, por el que se crea una Oficina Europea de Policía (Convenio Europol, DO C 316, de 27 de noviembre de 1995 , p. 2). Asimismo, este listado se introdujo como anexo II en el Documento 10415/00 del Consejo de la UE, de 3 de agosto de 2000, y se corresponde grosso modo con la relación de delitos incorporada con posterioridad a la orden europea de detención y entrega por los que se concederá la entrega sin verificación de la doble tipificación de los hechos (DO L 190, de 18 de julio de 2002, p. 1). 


\section{LA TIPIFICACIÓN DE LOS DELITOS DE PERTENENCIA}

En su art. 2, la DM insta a que los legisladores nacionales tipifiquen como delito la participación en una organización delictiva. Esta disposición, a pesar de la propuesta inicial de la Comisión, mantiene el doble modelo de participación del marco anterior: la "participación activa» en una organización delictiva y/o el «acuerdo». En cuanto al primero de ellos, la DM introduce algunas modificaciones para recoger los preceptos contenidos en la Convención de Palermo, ampliando considerablemente el ámbito cubierto por el delito de participación activa. Así, la participación activa en la organización delictiva se recoge en términos generales en la DM, sin que quepa diferenciar el grado de responsabilidad de cada miembro dentro de la organización o en la comisión de un delito. Esta cuestión ha sido objeto de críticas por buena parte de la doctrina penal por los riesgos que conlleva incriminar a un colectivo aludiendo a términos tan laxos como los introducidos por la normativa comunitaria.

Varios son los puntos más críticos de la DM en este sentido. En primer lugar, no se distingue entre los diversos grados de responsabilidad y autoría dentro del amplio espectro del delito de participación activa. Es decir, por un lado, los actos indispensables para conseguir los fines de la organización instigación, dirección o ejecución material del delito- $-y$, por otro, aquellas actividades subsidiarias o de apoyo a la organización, como serían proporcionar información relevante, financiación o reclutar a nuevos miembros para la organización (mera "participación delictiva»). En este caso, contrariamente a la distinción efectuada por la Acción Común, la DM diluye las diferentes actividades de autoría con las de participación delictiva, instando a los Estados miembros a tipificarlas indiscriminadamente como delito de participación. En segundo lugar, la DM tampoco distingue entre las conductas de autoría, instigación o colaboración necesaria; una diferenciación indispensable para garantizar la efectiva proporcionalidad de las sanciones impuestas a nivel penal estatal. En tercer lugar, además de la participación activa (principal o subsidiaria), es requisito que se tipifique a nivel nacional la simple "pertenencia» o membresía en organización delictiva, siendo sancionada con arreglo al art. 2 de la DM como delito autónomo, independiente de la autoría o de la comisión efectiva de un delito ${ }^{14}$ y del grado de implicación del miembro en su

14 A pesar de ello, hemos de poner este artículo en relación con el considerando núm. 5 de la DM. Mediante la inclusión de este considerando durante la tramitación de la DM, se permite que los legisladores nacionales interpreten que el término «actividades ilícitas» conlleve necesariamente la materialización de actividades delictivas concretas y efectivas para que sea tipificado y dé lugar a una incriminación posterior del individuo, no solamente la membresía en organización delictiva. 
ejecución o planificación. En cuarto y último lugar, se excluyen del ámbito cubierto por la DM aquellos delitos de mera «omisión», ya que se exige tipificar el carácter activo de la participación (Méndez Rodríguez, 2009: 20).

Adicionalmente, la tipificación de la pertenencia y participación activa requiere que el individuo sea consciente de que la organización comete actividades ilegales o su intención de perpetrarlas en un futuro próximo. Este requisito doloso ya venía recogido en la Acción Común de 1998 — ex art. 2.1.a)—, si bien la novedad radica ahora en que es obligatorio para incriminarlo que dicho individuo esté al tanto de que «su participación contribuirá al logro de la finalidad delictiva» de la organización. De esta forma, al contrario que para el caso de las personas jurídicas, la DM elimina la posibilidad de imputar a un individuo por imprudencia. Además, ese requisito doloso enlaza con la delincuencia de grupo o societas identificada tradicionalmente por la doctrina.

Por otra parte, la DM conserva el doble esquema de participación en organización delictiva instaurado previamente por la Acción Común al incluir la «conspiración» como segunda alternativa para tipificar este delito. En su art. 2.1.b), la DM permite que los Estados miembros tipifiquen el acuerdo o conspiracy, contradiciendo la propuesta de la Comisión destinada a simplificar la intervención europea mediante la introducción de un modelo coordinado único —además de contravenir el elemento de delincuencia de grupo analizado por la doctrina-. Mediante esta alternativa el legislador nacional puede tipificar como delito el acuerdo entre dos o más personas "para proceder a una actividad que, de ser llevada a cabo, suponga la comisión de delitos considerados en el artículo 1»; es decir, un delito grave. Se trata, por tanto, de un concierto entre varios individuos con carácter previo a la organización y, eventualmente, la posterior comisión de un delito grave. Además, como en la Acción Común, puede tipificarse «aun cuando esa persona no participe en la ejecución de la actividad». Por el contrario, a diferencia del marco anterior, la DM circunscribe su ámbito material a aquellos acuerdos relacionados obligatoriamente con las actividades de una organización delictiva. Esto implica una mejora, pues, en función de los grados de sanciones mínimos aplicables a los delitos graves objeto del acuerdo, se excluyen (en teoría) otras actividades de menor gravedad o conductas antisociales sancionadas con una pena inferior.

En consecuencia, a pesar de las evidentes lagunas de la DM, la tipificación de la participación en una organización delictiva crea el marco legal básico para sancionar al individuo por su mera pertenencia, independientemente de la materialización del delito concreto. A través de su normativización, se constituye en un delito autónomo, en sí mismo perseguible en todo el ELSJ. Además, la pertenencia a organización delictiva representa una circunstancia agravante a la hora de imponer las penas en el caso de la comisión de otros delitos (art. 3.2). Este marco ha permitido avanzar igualmente en el desarrollo 
estratégico y programático de esta política «común» contra el COT (Ruiz Díaz, 2015), si bien su repercusión en los ordenamientos internos estatales no ha sido tan amplia como se esperaba inicialmente, como veremos en el siguiente apartado. Es necesario, no obstante, insistir en que las novedades introducidas por la DM son escasas. En especial porque las instituciones comunitarias han obviado la oportunidad que el marco transnacional de Palermo ofrecía para profundizar la integración europea en este terreno, en particular en cuanto a la tipificación de la «dirección de una organización delictiva»o de otros delitos relacionados con el COT ausentes en la normativa comunitaria, como el blanqueo (art. 6 de la Convención), la corrupción (art. 8 y Convención de Naciones Unidas contra la Corrupción ${ }^{15}$ ) y la penalización de la obstrucción a la justicia (art. 23). Estas omisiones, claramente deliberadas por voluntad política, cuestionan la utilidad real de esta DM y de su impacto en los Estados miembros, sobre todo si se tiene en cuenta cómo se han implementado en materia de sanciones.

\section{SANCIONES}

Inicialmente, la DM aspiraba a superar las limitaciones del anterior marco comunitario en materia de sanciones. Sin embargo, como en el caso de las tipificaciones, la DM tampoco satisfaría las expectativas creadas en un principio por la propuesta de revisión de la Comisión. Según la Acción Común de 1998, las sanciones establecidas por los legisladores nacionales debían ser «efectivas, proporcionales y disuasorias». Esta amplitud dejaba un dilatado margen de maniobra a los Estados miembros a la hora de establecer las sanciones correspondientes según su ordenamiento, en función del grado de implicación del individuo. Con la adopción de la DM, se intentaba armonizar el nivel de sanciones penales en la UE fijando un grado mínimo de reclusión para los delitos de participación en organización delictiva. Así, el art. 3 de la DM fija para estos delitos una «pena máxima de reclusión de al menos entre dos y cinco años», más reducido que el propuesto inicialmente por la Comisión (Comisión Europea, 2005a: 6). Para el delito de «acuerdo" del apartado b), por su parte, la DM plantea dos opciones: 1) misma pena máxima de reclusión que la aplicable al delito objeto de la conspiración, o 2) una pena máxima de prisión de al menos entre dos y cinco años, como para el delito de participación.

15 Convención de Naciones Unidas contra la Corrupción, adoptada por Resolución 58/4 de la Asamblea General de Naciones Unidas, de 31 de octubre de 2003 (U.N.T.S., vol. 2349, p. 41). 
Estos umbrales en el establecimiento de las sanciones buscaban, en definitiva, agilizar la cooperación judicial en el seno de la Unión, sumándose así a disposiciones similares en otras normas del ELSJ, como la orden europea de detención y entrega (o euroorden) ${ }^{16}$. Sin embargo, este nivel de sanciones resulta ser posiblemente inferior al que debiera corresponderle por la supuesta gravedad de las actividades criminales de estas organizaciones y del peligro que este tipo de grupos representa para la economía y la sociedad europeas, tal y como se reconoce en el art. 1. Además, dicha peligrosidad es el fundamento mismo de la necesidad de tipificar la pertenencia a organización delictiva como delito autónomo. Por otra parte, este umbral contradice al pactado por el Consejo en 2002 sobre los niveles de sanciones penales y las categorías de delitos en función de su gravedad (Consejo de la Unión Europea, 2002). De hecho, por ejemplo, el Código Penal español establece como graves aquellos delitos para los que está prevista una pena de, como mínimo, cinco años de prisión, mientras que las sanciones previstas por la DM entrarían en la categoría de menos graves atendiendo a las penas impuestas por nuestro ordenamiento (art. 33 del Código Penal español).

En verdad, este umbral fijado por la DM sufrió una rebaja considerable durante su tramitación en el Consejo. Entre las dudas suscitadas por algunos Estados miembros en la negociación del texto, los países nórdicos se manifestaron contrarios a castigar con una pena mayor de dos años la participación en organización delictiva al no prever específicamente en sus códigos penales este tipo por considerarlo contrario al principio de libertad de asociación, constitucionalmente reconocido en sus ordenamientos internos ${ }^{17}$. De esta forma, en Suecia y Dinamarca la membresía a este tipo de grupos no es delito por sí mismo, por lo que los jueces de otros Estados miembros deberían alegar otras infracciones para poder recibir ayuda de sus homólogos suecos y daneses (Calderoni, 2010: 65-74). Estas reservas se observan también en la práctica seguida por las autoridades judiciales de otros Estados miembros. Así, por ejemplo, en Alemania, si bien recoge en su código penal esta tipificación, «el delito de

16 Art. 2.2 de la Decisión Marco 2002/584/JAI del Consejo, de 13 de junio de 2002, relativa a la orden de detención europea y a los procedimientos de entrega entre Estados miembros (DO L 190, de 18 de julio de 2002, p. 1).

17 El Senado francés se hizo eco del debate del Consejo, donde se deja notar ese clivage en el seno de la Unión entre distintos sistemas penales y constitucionales; es decir, escandinavo, europeo continental y de common law anglosajón. Sobre este punto, véase, Conclusions de la commission sur la proposition du sénateur FAUCHON, de 11 de abril de 2006 [Texte E 2839 - COM (2005) 6 final], disponible en: http:// www.senat.fr/ue/pac/E2839.html. 
asociación es raramente utilizado» por los impedimentos que se plantean a la hora de imponer las sanciones (Manacorda, 2002: 15).

La DM se ha enfrentado igualmente a otros retos en este punto relativo a las penas. Además de las dificultades en relación con la prueba de los elementos característicos de organización delictiva, el derecho penal debe afrontar el reto de sancionar la pertenencia con la misma pena que a los autores materiales de un delito cometido en su seno, a pesar de que es "común en los sistemas penales modernos reflejar en la entidad de la pena el grado de ejecución del delito» (Méndez Rodríguez, 2009: 22). Igualmente, el derecho penal tradicional ha expresado sus inquietudes ante la eventual sanción por la peligrosidad de la pertenencia de un individuo a una organización delictiva y no por la gravedad del delito finalmente cometido en su seno, rompiendo con uno de sus principios clásicos, el de proporcionalidad. Por ello, este umbral que establece la DM es congruente con esos temores del juez nacional, ya que la judicatura ha optado por aludir al delito de participación como agravante en la imposición de las penas, apelando a esta figura «solamente en ausencia de otros delitos susceptibles de proporcionar a la acusación perspectivas de éxito» (Manacorda, 2002: 62).

Por otra parte, la participación en organización delictiva ha sido igualmente codificada como circunstancia agravante en la DM (art. 3.2). Con ella, se pretende que el juez nacional imponga una pena superior o más rigurosa en el caso de que un delito se haya cometido en el marco de una organización delictiva, en función de la gravedad del delito y del peligro que representan estos grupos. Esta agravante no supone una innovación en el contexto europeo, ya estaba prevista en algunos Estados miembros para determinados delitos, estuvieran o no conectados con el COT, como los tráficos ilícitos de drogas o armas y la trata de seres humanos. Además, la UE había incorporado esta circunstancia agravante en otros textos legales en el ámbito penal, que igualmente atañen a la lucha contra el COT. Por último, también se prevé en la DM una cuestión novedosa en el marco europeo - aunque tremendamente controvertida en la práctica (Cesoni, 2007; Núñez y Guillén, 2009)_, igualmente recogida en el marco transnacional de Palermo: la posible atenuación de las penas e, incluso, su inaplicación para quienes, arrepentidos, abandonan la actividad criminal y proporcionan a las autoridades información de interés para la investigación de los delitos (art. 4), con el fin de que esta colaboración con las autoridades judiciales y policiales ayude a desmontar una organización delictiva o impida la comisión de sus actividades ilícitas. Es de lamentar, no obstante, que no se tuviera en cuenta en su día la opinión del Parlamento Europeo, que solicitó penas complementarias de inhabilitación y el decomiso de los bienes producto del delito como elemento preventivo y disuasorio de la actividad delictiva (Parlamento Europeo, 2006). Además, hubiera significado 
un alineamiento del derecho penal europeo con el marco transnacional de Palermo.

\section{BALANCE DE LA DECISIÓN MARCO. ¿̇HA SUPUESTO UN CAMBIO REAL EN LA POLÍTICA CRIMINAL DE LOS ESTADOS MIEMBROS Y DE LA UNIÓN EUROPEA?}

\section{EVALUACIÓN GENERAL DEL IMPACTO DE LA DECISIÓN MARCO EN EL ORDENAMIENTO DE LOS ESTADOS MIEMBROS}

Como era más que previsible, la implementación de la DM ha dejado mucho que desear. En particular, no ha supuesto una mayor armonización de las legislaciones penales de los Estados miembros, ni ha resuelto los principales interrogantes planteados cuando se adoptó la Acción Común. Desde el punto de vista del derecho penal, la DM no cumple con las expectativas creadas en cuanto al grado de armonización previsto por la propuesta de la Comisión, que se desmarcó del documento finalmente adoptado por considerar que no lograba «el grado mínimo de aproximación de los actos de dirigir o participar en una organización criminal» (Consejo de la Unión Europea, 2006: 12). Por todo lo analizado en las líneas precedentes, es evidente que la aportación de la DM a la integración del espacio judicial europeo es bastante limitada, tanto por mantener el doble modelo de participación heredado del marco comunitario anterior, como por resultar parcial y sectorial en comparación con la Convención de Palermo, que insta a los Estados parte a tipificar un abanico más amplio de delitos relacionados con el COT (por ejemplo, dirección de organización delictiva) y aquellos que facilitan su expansión (corrupción, blanqueo de capitales y obstrucción de la justicia), obviados claramente por la DM. Por último, Estados miembros como Dinamarca y Suecia han optado por no tipificar la participación como delito autónomo, mientras que otros que sí la consideran limitan la aplicación del delito de participación en una organización delictiva a "circunstancias que implican el uso de intimidación, amenaza, violencia, fraude, corrupción o estructuras comerciales», como Bélgica (Comisión Europea, 2016: 5).

Con independencia del modelo de participación elegido, resulta patente que definir en negativo "organización delictiva", como lo hace la DM, ha dejado un margen de maniobra muy amplio al legislador estatal para delimitar el concepto y establecer los elementos que considere más oportunos incluir en su ordenamiento interno. Así, por ejemplo, en España se han incorporado en nuestro ordenamiento requisitos adicionales, mientras que otros recogidos en la DM han sido eliminados (véanse arts. 570 bis y ter del Código Penal y 
282 bis.4 LECRim). Como consecuencia de la amplitud de los términos de la DM, los cambios en los Estados miembros han sido mínimos, como muestra, por ejemplo, el caso francés y el mantenimiento en su legislación penal de la association de malfaiteurs, un concepto mucho más amplio y difuso que el de organización delictiva de la DM al no requerir la permanencia temporal o estructura alguna. Igual sucede en otros Estados miembros que no incluyen ninguno de estos elementos, como Alemania, Eslovenia, Italia, Letonia, Malta, Países Bajos y Polonia. Mientras, otros (Suecia y Dinamarca) no creen conveniente tipificar la membresía como un delito autónomo por considerar que afectaría a la libertad de asociación de su ciudadanía. En definitiva, esta amplitud terminológica y la vaguedad de los conceptos empleados por la DM han sido generosamente explotadas por los Estados miembros para conservar su legislación sin introducir apenas cambios o para incluir modificaciones insustanciales, como afirman tanto la doctrina (Calderoni, 2010; Mitsilegas, 2011) como las instituciones europeas (Comisión Europea, 2016; Parlamento Europeo, 2011). En algunos casos, dichas reformas han estado motivadas más por criterios internos de los legisladores nacionales que por la necesidad de cumplir con las disposiciones de la DM (Di Nicola et al., 2014).

Por otra parte, también en el ámbito del establecimiento de las sanciones se ha visto mermada la supuesta armonización pretendida inicialmente al contemplar la gravedad del delito en términos cuantitativos, según lo estipulado en el art. 1 de la DM, y no cualitativos o con arreglo a un listado de delitos principales graves como hubiera sido deseable. En primer lugar, la participación (activa) en organización delictiva es sancionada en los ordenamientos de los Estados miembros con penas privativas de libertad muy dispares, que oscilan entre los dos hasta los ocho años como mínimo (Finlandia y Letonia, respectivamente) a los diecisiete años como máximo (Letonia), aparte de las sanciones de reclusión previstas en aquellos países en los que está tipificada la conspiración (Bulgaria, Croacia, Grecia y Malta), considerablemente más bajas que el resto. En segundo lugar, la mayoría de los Estados miembros ha incorporado sanciones más severas a las previstas en la DM para determinadas conductas agravadas, en función de la gravedad del delito cometido o de la posición concreta del individuo en la estructura organizativa, por ejemplo, en el caso de la dirección de la organización. Asimismo, aunque seis no contemplan esta posibilidad (Estonia, Francia, Grecia, Luxemburgo, Países Bajos y Rumanía), existe disparidad en cuanto a la consideración del delito de participación como agravante en la mayoría de los Estados miembros que sí lo prevén, siendo unánime la instauración de condicionantes para ello, bien en atención al mínimo de reclusión previsto a nivel interno (Eslovenia e Irlanda), bien respecto a una lista de delitos principales graves perpetrados en el seno de una organización delictiva (Alemania, Austria, Bélgica, Bulgaria, Chipre, 
Eslovaquia, España, Italia, Letonia, Malta y Portugal) o para cualquier tipo de delito, independientemente de la gravedad del mismo (Croacia, Finlandia, Hungría, Lituania, Polonia y República Checa). Por último, las sanciones previstas para las personas jurídicas varían ampliamente de un Estado miembro a otro, pudiendo ser penales o meramente administrativas y de aplicación otras medidas adicionales diferentes de las multas, previstas por la mayoría de Estados miembros, como la exclusión del disfrute de ventajas o ayudas públicas.

Por ello, dada la diversidad en el establecimiento de sanciones hubiera resultado más conveniente implantar un listado (ampliable) de delitos calificados siempre como graves dentro de la UE o de otros que debieran ser tipificados independientemente de la gravedad, como recoge la Convención de Palermo y estipulan algunos ordenamientos estatales e, incluso, en la propia euroorden. Además de facilitar la prevención y represión del COT, permitiendo una mayor coordinación de las autoridades estatales, sería un buen elemento para reforzar la confianza mutua entre jurisdicciones, al poseer un denominador común independiente del grado de sanción prevista para el delito de participación en un Estado miembro u otro. De hecho, ante el escaso éxito obtenido por la $\mathrm{DM}$ en relación con la armonización de las sanciones, se presta necesaria la instauración de instrumentos de coordinación que impidan un abuso de esta figura de participación en organización delictiva por parte de determinadas autoridades nacionales aludiendo al mismo para el enjuiciamiento de un individuo por infracciones menores, como se ha observado en la práctica de la euroorden (Sousa Santos, 2010).

Para la criminología tampoco ha resultado satisfactoria la DM. Como analizamos en las líneas precedentes, la DM deja fuera de su ámbito material ciertos elementos que se consideran indispensables desde el punto de vista criminológico para considerar una organización delictiva y que, en último término, justifican la intervención comunitaria. Este hecho ha producido una implementación dispar en los ordenamientos internos de los Estados miembros, que han aprovechado la flexibilidad de la DM para minimizar su impacto real. Los requisitos mínimos incluidos en las definiciones aportadas por la DM para calificar como tal a una organización delictiva resultan ambiguos y amplios si nos atenemos a la necesaria claridad de los términos para que, desde el punto de vista penal, garanticen un mínimo de seguridad jurídica; pero también se tornan desatinadamente genéricos para la criminología. La delimitación del concepto por la DM es prácticamente inexistente, pues define la organización delictiva en términos muy amplios, abriendo la posibilidad de dar cabida a diversos fenómenos delictivos sin aparente conexión con el COT. De esta forma, los elementos de «estructura» $y$ "continuidad» se ven reducidos al mínimo en la DM, planteándose la interrogante de si nos encontramos en realidad ante una organización delictiva con un horizonte 
temporal independiente de los individuos que la componen o ante un simple acuerdo para delinquir de un grupo de personas con un cometido específico y limitado en el tiempo. Además, contrariamente al marco transnacional de Palermo, en ningún momento alude la DM a otros elementos característicos del COT según la criminología, como el uso o la amenaza de la violencia, la extorsión y la corrupción.

En realidad, la laxitud y vaguedad de los términos en la DM es un reflejo de la tradicional ambigüedad conceptual de la UE en relación con el COT, cuestión que ha tenido un claro impacto en su transposición en los ordenamientos internos. De hecho, como recoge la Comisión en su informe de implementación, solamente tres Estados miembros (Bélgica, Eslovaquia y Luxemburgo) han incluido expresamente en sus ordenamientos internos el criterio de la obtención del beneficio económico o material, dejando abierta la posibilidad de que se aplique esta normativa interna a otro tipo de organizaciones delictivas o asociaciones no necesariamente ligadas al COT, como ha sucedido en la práctica (Di Nicola et al., 2014). Es por todo lo analizado anteriormente que la DM repite los fallos del marco anterior, desdibujando el elemento preventivo y, en general, perjudicando la respuesta coordinada de la UE contra el COT al instaurar cierta inseguridad jurídica que menoscaba claramente la implementación del reconocimiento mutuo de resoluciones judiciales y de admisión de pruebas.

Años más tarde tras su adopción, en 2013, el Parlamento Europeo volvería a recordar en el «Informe Iacolino» las principales lagunas de la DM. En él, la Eurocámara pedía que la Comisión propusiera una revisión legislativa para incorporar en el ordenamiento comunitario una definición común que incluyese, como mínimo, las notas relativas al espíritu empresarial del COT, el poder de intimidación de estas organizaciones y su estructura organizativa (Parlamento Europeo, 2013), como recoge la Convención de Palermo y se ha tipificado en algunos Estados miembros. Solamente unos años después, los europarlamentarios volverían a solicitar una normativa europea más precisa y detallada en determinados ámbitos de la lucha contra el COT (Parlamento Europeo, 2016). Es clara, por tanto, la necesidad de colmar las lagunas del marco normativo europeo con un instrumento mucho más eficaz y coherente con la peligrosidad del COT. Dicha reforma, además de estar en línea con el planteamiento estratégico de la Unión y las disposiciones del marco transnacional de Palermo, tomaría en consideración los recientes compromisos internacionales adquiridos por la UE en el seno del Consejo de Europa, que viene a sumar al marco transnacional nuevos instrumentos que reafirman la necesidad de mejorar la coordinación multilateral y la cooperación internacional contra el COT y de implementar eficazmente la legislación existente para atajar este 
fenómeno criminal ${ }^{18}$. Sin embargo, parece que los Estados miembros se muestran generalmente satisfechos con la flexibilidad que les proporciona el actual marco europeo ${ }^{19}$, desincentivando cualquier iniciativa al respecto por parte de los servicios de la Comisión en el corto plazo.

\section{LAS PRINCIPALES LAGUNAS Y CUESTIONES POR RESOLVER}

La Comisión reconoce en su informe las principales carencias en la implementación de la DM y se reafirma en que, con este instrumento, no se ha alcanzado el grado mínimo de aproximación necesario (Comisión Europea, 2016). Dicho esto, algunos de estos vacíos son merecedores de especial atención por las implicaciones que acarrean para el conjunto del ELSJ y, en concreto, del espacio judicial europeo y la implementación en la práctica de uno de sus principios cardinales: el reconocimiento mutuo. Primeramente, hemos de insistir en la necesidad de aclarar los términos de las definiciones empleadas, como solicitara la Eurocámara en repetidas ocasiones (Parlamento Europeo, 2006, 2013 y 2016). De lo analizado anteriormente no se deduce que la DM emplee con claridad ciertas definiciones, cuya ambigüedad ha sido plenamente aprovechada por los Estados miembros para no realizar prácticamente ningún cambio legislativo en su transposición interna; ni de los términos utilizados para avanzar en la integración penal y la lucha contra el COT a nivel europeo, pues muchos de ellos acaban siendo utilizados como «cajón de sastre» en caso de no encontrar fundamento legal en los tratados para la intervención comunitaria. Así, por ejemplo, en la UE se alude a COT y delincuencia organizada y/o grave en los documentos de evaluación de la amenaza e informes de Europol en los que se basa el ciclo de intervención de la UE y, en consecuencia, su acción en materia de aproximación legislativa.

Esta (calculada) indefinición terminológica se torna problemática y exige de una mayor precisión en el marco legal comunitario. Especialmente, resulta indispensable si consideramos los particulares procedimientos de investigación seguidos, la posibilidad de ampliar los plazos de la detención preventiva y de algunas medidas de seguridad privativas de libertad específicas que los jueces pueden tomar ante este tipo de organizaciones criminales, además del

18 Consejo de Europa (2015), White Paper on Transnational Organized Crime; Consejo de Europa (2016), Council of Europe Action Plan on Combating Transnational Organized Crime (2016-2020), CDPC (2015) 17 Fin. Ambos documentos están disponibles en: https://www.coe.int/.

19 Observación realizada por los servicios competentes de la Comisión Europea en el marco de una entrevista personal realizada en junio de 2018. 
decomiso de capitales ampliado y de los particulares métodos de investigación policial; medidas que nos acercan más a un «derecho de excepción generalizado» (Cesoni, 2007) que a una intervención de última ratio dentro de una política criminal europea coherente. Por ello, es evidente que el actual marco de lucha contra el COT establecido en estos últimos años en la UE — del cual esta DM es únicamente una muestra- puede llegar a quebrantar la tutela judicial de los derechos fundamentales de los investigados e inculpados si no se incorporan las suficientes garantías procesales a los ordenamientos de los Estados miembros o la judicatura interpreta la norma europea con la diligencia que esta divergencia normativa y sancionadora resultante demanda. Además, está por justificar todavía la utilidad práctica de tipificar la participación en organización delictiva con independencia de la ventaja que supone para las autoridades estatales extender el alcance de la investigación judicial y policial del COT a otros sectores relacionados y, en consecuencia, mejorar la efectividad de la prevención y represión de este fenómeno delictivo. Puede, incluso, llegarse a dudar de la legalidad de estas actuaciones policiales y judiciales con recurso a las medidas excepcionales propugnadas por la DM, que no se han visto compensadas con un fortalecimiento de las garantías procesales a nivel de la UE, integradas actualmente en el marco comunitario en su mínimo común denominador (Flore, 2014: 327-435; Peers, 2011: 675-749). De la práctica seguida hasta ahora por autoridades policiales y judiciales se desprende, no obstante, que los instrumentos comunitarios han servido más al carácter represivo o punitivo de la respuesta común que a la finalidad preventiva prevista en la mayoría de iniciativas legislativas en esta materia (Comisión Europea, 2016; Sousa Santos, 2010).

Continuando en el terreno procesal, en principio una de las mejoras más relevantes de la DM ha sido la incorporación al derecho de la UE de una norma, hasta cierto punto, más precisa en relación con los posibles conflictos de jurisdicción. Su alcance, sin embargo, ha estado claramente condicionado a su transposición al ordenamiento interno por los Estados miembros ante las numerosas disposiciones facultativas incluidas en la DM. La regla básica de la que parte el art. 7 es el principio tradicional de «territorialidad», al que viene a sumarse el de "personalidad" activa y pasiva. Partiendo de esa base, los Estados miembros tienen que delimitar sus competencias para enjuiciar los delitos tipificados con arreglo a la DM (participación activa o acuerdo) que se ejecuten o planifiquen en su territorio, total o parcialmente, independientemente del Estado miembro en el que la organización delictiva opere, esté radicada o blanquee los productos de sus actividades criminales. Además, de manera facultativa, los Estados miembros podrán extender su jurisdicción extraterritorialmente bien mediante la competencia personal, bien cuando el 
delito se haya perpetrado «en beneficio de alguna persona jurídica establecida en el territorio de dicho Estado miembro».

A pesar de lo que pudiera parecer en un primer momento, el alcance de este precepto relativo al establecimiento de la jurisdicción competente es más limitado que el correspondiente en el marco anterior. La extinta Acción Común demandaba de la autoridad judicial una intervención preceptiva en caso de existir un vínculo territorial, incluso si no concurrían otros nexos de competencia, planteando en algunos casos un posible conflicto (positivo) de jurisdicción. La mejora que plantea la DM para zanjar potenciales conflictos de jurisdicción radica en establecer un criterio de mínimos relativamente más operativo que el contenido en la Convención de Palermo, al obligar a las autoridades de los Estados miembros a colaborar previamente, recurriendo — si fuera necesario- a Eurojust u otros actores del ELSJ, como la Fiscalía Pública Europea en caso de ampliar su competencia a estos delitos. No obstante, la implementación de este precepto sigue dependiendo en la práctica de la voluntad de colaboración de las autoridades estatales, puesto que se les deja un amplio margen de maniobra en la valoración de los medios de cooperación y su obligatoriedad, dado el carácter facultativo de las medidas propuestas; un esquema que se repite en otras normas aplicables en materia de resolución de conflictos de jurisdicción en el ELSJ ${ }^{20}$, manteniendo el tradicional enfoque comunitario sobre jurisdicción, al servicio de los Estados miembros individualmente considerados (Klip, 2009: 187). Dada la amplitud de los términos empleados, de los elementos finalmente incluidos en la definición de los tipos a nivel nacional y de las sanciones impuestas a nivel interno, hubiera sido preferible incluir alguna regla más clara y preceptiva para la delimitación de la jurisdicción competente o en mejor posición para conocer del caso, en particular teniendo en cuenta que el criterio de «territorialidad» no es siempre el más importante en la casuística de Eurojust y se siguen planteando conflictos de jurisdicción complejos entre EEMM en la investigación de delitos en los que participan organizaciones delictivas (Eurojust, 2018: 9; Ruggeri, 2015: 219-220).

También la DM ha dejado la puerta abierta a incluir otras incógnitas no resueltas en el marco europeo, esta vez relacionadas con la prevención del delito en términos generales. Así, a través de una serie de iniciativas, en los últimos

20 Este marco específico de colaboración se completa con la Decisión Marco relativa a la prevención y resolución de conflictos de ejercicio de jurisdicción en los procesos penales (2009/948/JAI del Consejo, de 30 de noviembre de 2009, DO L 328, de 15 de diciembre de 2009, p. 42), así como por las disposiciones específicas de la euroorden (DO L 190, de 18 de julio de 2002, p. 1) y la Decisión por la que se establece Eurojust (2002/187/JAI, DO L 63, de 6 de marzo de 2002, p. 1, y actos modificativos). 
años la UE ha instrumentalizado el decomiso, convirtiéndolo en una pieza más de una estrategia más global de prevención del delito y, en particular, de la lucha contra el COT, adquiriendo una incuestionable componente preventiva que ha alterado claramente su naturaleza (Jiménez-Villarejo, 2011). En línea con este cambio de enfoque, perceptible tanto a nivel nacional como internacional, la UE ha configurado un marco normativo relativamente amplio para proteger al sistema financiero y bancario contra el blanqueo de los productos del delito o, en general, proteger la integridad del sistema financiero comunitario (Siclari, 2016; Marletta, 2016). De manera particular, si bien la DM analizada no incluye ninguna disposición al respecto, la directiva de 2014 referente al decomiso de los productos del delito ${ }^{21}$ regula el marco europeo y busca evitar que los fondos ilícitamente obtenidos por las organizaciones delictivas sirvan para cometer nuevos delitos. Para ello, esta directiva armoniza el «decomiso ampliado» y pretende afianzar el reconocimiento mutuo tanto de medidas temporales (por ejemplo, el embargo preventivo y la confiscación de bienes), como de resoluciones judiciales que, con carácter definitivo, permitan el embargo de los productos del delito y/o de los bienes empleados para su comisión. Además, los Estados miembros deberán adoptar medidas de decomiso ampliadas en caso de que el delito se haya cometido en el seno de una organización delictiva, posibilitando que los jueces puedan, asimismo, decomisar (total o parcialmente) otros bienes que consideren igualmente sean producto de otros delitos relacionados, a los que vendrían a sumarse aquellos de los allegados y de las personas jurídicas bajo su control.

La normativa europea sobre el decomiso introduce, no obstante, las indefiniciones que le son propias al derecho europeo penal. Esta norma marco permite que sean las autoridades judiciales de los Estados miembros quienes determinen, atendiendo a unos criterios vagamente definidos, el alcance real de estas medidas de prevención a través del decomiso de bienes e instrumentos del delito. Así, el marco comunitario aprueba que la autoridad judicial estatal ejecute el decomiso en ausencia del acusado durante la tramitación e, incluso, la incoación del expediente, una posibilidad que no está prevista en todos los Estados miembros. Igualmente, el decomiso ampliado previsto por la directiva puede vulnerar las garantías procesales del inculpado o investigado, en particular en cuanto a su presunción de inocencia (Díaz Cabiale, 2016: 36). En el caso de España, por ejemplo, su implementación en el ordenamiento interno ha supuesto ampliar de manera «desproporcionada» el alcance de la posibilidad

21 Directiva 2014/42/UE del Parlamento Europeo y del Consejo, de 3 de abril de 2014, sobre el embargo y el decomiso de los instrumentos y del producto del delito en la Unión Europea (DO L 127, de 29 de abril de 2014, p. 39). 
de confiscar bienes por un valor «equivalente» a los que se presumen obtenidos de forma ilegal basándose en indicios y no pruebas directas (Roig Torres, 2016: 251). Hubiera sido conveniente incluir en la DM algún precepto sobre las medidas necesarias para poder proceder con todas las garantías al embargo y decomiso ampliado en el marco de las técnicas e instrumentos especiales de lucha contra el COT, como ha propuesto hasta en dos ocasiones la Eurocámara (Parlamento Europeo, 2006 y 2011), fundamentalmente en aquellos casos que tengan carácter preventivo o en ausencia de condena. Además, hubiera sido deseable introducir una definición clara de los términos «productos del delito» (más amplio) y «beneficio económico» (más restringido), e insistir en que estas medidas no se encuentren ligadas únicamente a los supuestos en los que las actividades delictivas de estos grupos hayan representado un beneficio económico, como apunta esta directiva (art. 5.2), sino que sean aplicables a la comisión de delitos graves por dichas organizaciones delictivas en todo caso.

Por todo lo analizado a lo largo de estas líneas, ahora más que nunca se hace necesario avanzar para colmar las lagunas observadas tanto en el ámbito material como procesal del marco comunitario contra el COT. Pasos en este sentido servirían para afianzar la confianza mutua entre las autoridades policiales y judiciales de los Estados miembros, antes de que sea demasiado tarde y las disparidades y la mala praxis de la judicatura hagan inviable el buen funcionamiento del espacio judicial europeo, como se está dejando entrever en relación con otros instrumentos en este sentido — por ejemplo, la euro-orden (Sousa Santos, 2010)—.

\section{CONCLUSIONES}

La implementación de la DM en los ordenamientos internos de los Estados miembros ha dejado más interrogantes que dudas despejadas. Por regla general, los legisladores nacionales han aprovechado plenamente las indefiniciones del texto comunitario para, de una parte, realizar pocos cambios a nivel de tipificación de delitos y, de otra, superar con creces el umbral de la $\mathrm{DM}$ a la hora de establecer sanciones y otras medidas con carácter preventivo y represivo de aplicación tanto a personas físicas como jurídicas. Así, determinadas disposiciones que, en principio, eran facultativas según la DM, fueron finalmente incorporadas en su trasposición en derecho interno en buena parte de los Estados miembros. Esta disparidad es especialmente problemática en relación con los elementos que tienen en cuenta los Estados miembros para tipificar la participación en organización delictiva, a los diferentes tipos de participación empleados en el espacio judicial europeo no resueltos por la DM y, en general, a las poco precisas definiciones ofrecidas por el 
marco comunitario; una calculada obscuridad en el uso del lenguaje que, no olvidemos, ha sido completamente explotada por la UE para avanzar en la integración en este ámbito en aras de una supuesta urgencia en la intervención comunitaria para atajar el COT y, en consecuencia, proteger el espacio europeo de esta amenaza a la seguridad.

Esta asimetría en la trasposición de la DM en los ordenamientos internos afecta, sin duda, a la efectiva implementación de las medidas adoptadas tanto en el ámbito represivo como preventivo. Por una parte, las considerables disparidades en la tipificación de los delitos de participación en organización delictiva y de los elementos constitutivos del tipo en cada ordenamiento dificultan una fluida cooperación entre autoridades judiciales de diferentes Estados miembros, como han puesto de manifiesto tanto la doctrina como Eurojust, las cuales siguen acudiendo al delito de participación como último recurso, en ausencia de otro delito autónomo para iniciar una investigación o incoar un proceso judicial transfronterizo especialmente complejo. No obstante, el delito de pertenencia a organización delictiva es, además de circunstancia agravante en el establecimiento de penas, uno de los delitos que no es objeto de verificación de la doble incriminación en buena parte de normas comunitarias del ELSJ, siendo igualmente objeto de entrega entre Estados miembros a pesar de las diferencias legislativas observadas en la implementación de la DM. Por otra, la DM no incorpora ninguna disposición específica sobre los instrumentos y técnicas de investigación especiales que suelen ser de aplicación a la lucha contra el COT tanto a nivel interno como internacional, previstos en la Convención de Palermo y en otros textos europeos en aparente perenne letargo, como las disposiciones del título III «Policía y Seguridad» del Convenio de Aplicación del Acuerdo Schengen ${ }^{22}$. Así, determinadas medidas destinadas a la prevención del delito, como el decomiso de los productos e instrumentos del delito, y cautelares, tal que el embargo preventivo y el aseguramiento de pruebas, carecen de regulación específica en la DM y son objeto de normativización separada. Mientras, siguen siendo una rara avis en la práctica transfronteriza de las autoridades judiciales de los Estados miembros por los obstáculos observados, que, sin embargo, transcienden del objeto de nuestro estudio.

Por todo ello, directa e indirectamente, la disparidad de las disposiciones nacionales de implementación de la DM afecta a la consumación del principio del reconocimiento y confianza mutuos como piezas angulares del ELSJ,

22 Acervo de Schengen tal como figura en el apdo. 2 del art. 1 de la Decisión 1999/435/ CE del Consejo, de 20 de mayo de 1999 (DO L 239, de 22 de septiembre de 2000, p. 1). 
poniendo en valor los recelos expresados especialmente por los penalistas. Habiendo pasado diez años desde la adopción de un texto ya de por sí «descafeinado» en el momento de su publicación y tras su errática trasposición al ordenamiento interno de los Estados miembros, es clara la necesidad de plantear una reforma en profundidad del actual marco legal comunitario para atajar el COT de la forma más efectiva posible en sus diversas facetas; un marco que, además, tenga en cuenta las novedades del ELSJ acaecidas desde entonces -incluyendo el pleno potencial ofrecido por el derecho originario tras la entrada en vigor del Tratado de Lisboa- y los compromisos internacionales adquiridos por la UE. La nueva norma que reforme o sustituya a la DM debería tener en cuenta tanto las lagunas materiales como procesales analizadas en el presente estudio, pero también enmarcarse de manera coordinada en el conjunto de iniciativas e instrumentos en vigor de la pretendida política de derecho penal de la UE, esbozada por la Comisión en 2011, y estar en línea con los objetivos planteados en la Agenda Europea de Seguridad a largo plazo. Sin embargo, no parece que la revisión de la DM de 2008 entre en los planes más inmediatos de la actual Comisión al no estar recogida en el programa de trabajo para este año, ni que sea el momento (político) idóneo para presentar una propuesta legislativa de esta envergadura, en particular teniendo en cuenta que ahora el Parlamento Europeo es colegislador en la materia y las autoridades de los Estados miembros se encuentran «cómodas» con la flexibilidad que la vigente DM les otorga. Además, la convocatoria de elecciones europeas para mayo de 2019 podría alterar y retrasar sine die cualquier iniciativa a este respecto. Mientras, aunque imperfecta y de dudoso legado, parece que la DM seguirá siendo la pieza fundamental en el marco legal y operativo contra el COT en la UE por unos cuantos años más.

\section{Bibliografía}

Aleo, S. (2002). «The Definition and Repression of Organized Crime». En F. Longo (ed.). The European Union and the Challenge of Transnational Organised Crime (pp. 61-75). Milano: Giuffrè Editore.

Calderoni, F. (2010). Organized Crime Legislation in the European Union. Harmonization and Approximation of Criminal Law, National Legislations and the EU Framework Decision on the Fight Against Organized Crime. Heidelberg: Springer. Disponible en: https://doi.org/10.1007/978-3-642-04331-4.

Cesoni, M. L. (2007). Nouvelles méthodes de lutte contre la criminalité: La normalisation de l'exception. Étude de droit comparé (Bélgique, États-Unis, Italie, Pays-Bas, Allemagne, France). Bruxelles: Bruylant. 
Choclán Montalvo, J. A. (2001). Criminalidad organizada: concepto, la asociación ilícita, problemas de autoría y participación. Cuadernos de Derecho Judicial, 2, 215-268.

Comisión Europea. (2005a). Propuesta de decisión marco del Consejo relativa a la lucha contra la delincuencia organizada, COM (2005) 6 final, 19-1-2005.

Comisión Europea. (2005b). Desarrollo de un concepto estratégico para hacer frente a la delincuencia organizada, COM (2005) 232 final, 2-6-2005.

Comisión Europea. (2008). Productos de la delincuencia organizada. Garantizar que «el delito no resulte provechoso», COM (2008) 766 final, 20-11-2008.

Comisión Europea. (2011). Hacia una política de Derecho penal de la UE: garantizar la aplicación efectiva de las políticas de la UE mediante el Derecho penal, COM (2011) 573 final, 20-9-2011.

Comisión Europea. (2016). Informe de la Comisión al Parlamento Europeo y al Consejo basado en el artículo 10 de la Decisión Marco 2008/841/JAI del Consejo, de 24 de octubre de 2008, relativa a la lucha contra la delincuencia organizada, COM (2016) 448 final, 7-7-2016.

Consejo de la Unión Europea. (2000). Revisión del doc. 6204/2/97 ENFOPOL 35 REV 2, basado en el doc. 8469/1/99 CRIMORG 55 REV 1, 10415/00, 3-82000.

Consejo de la Unión Europea. (2002). Conclusiones del Consejo sobre el enfoque que debe seguirse para la aproximación de las penas, 9141/02, 27-5-2002.

Consejo de la Unión Europea. (2006). Propuesta de Decisión marco del Consejo relativa a la lucha contra la delincuencia organizada, 9067/06, 10-5-2006.

Cressey, D. R. (1969). Theft of the Nation. The structure and operations of organized crime in America. New York: Harper and Raw Publishers.

Di Nicola, A., Gounev, P., Levi, M., Rubin, J. y Vettori, B. (2014). Study on paving the way for future policy initiatives in the field of fight against organised crime: the effectiveness of specific criminal law measures targeting organised crime. Luxemburgo: Oficina de Publicaciones de la Unión Europea.

Díaz Cabiale, J. A. (2016). El decomiso tras las reformas del Código Penal y la Ley de Enjuiciamiento Criminal de 2015. Revista Electrónica de Ciencia Penal y Criminología, 18 (10), 1-70.

Eurojust (2018). Report on Eurojust's casework in the field of prevention and resolution of conflicts of jurisdiction. La Haya. Disponible en: http://www.eurojust.europa. $\mathrm{eu} /$.

Europol (2004). Informe 2004 de la Unión Europea sobre la delincuencia organizada (versión pública). La Haya. Disponible en: https://www.europol.europa.eu/.

Finckenauer, J. O. (2005). Problems of definition: What is organized crime? Trends in Organized Crime, 8 (3), 63-83. Disponible en: https://doi.org/10.1007/ s12117-005-1038-4

Flore, D. (2014). Droit pénal européen. Les enjeux d'une justice pénale européenne. Bruselas: Éditions Larcier.

González Rus, J. J. (2014). La criminalidad organizada. Valencia: Tirant lo Blanch. 
Hagan, F. E. (2006). "Organized Crime" and "organized crime": Indeterminate Problems of Definition. Trends in Organized Crime, 9 (4), 127-137. Disponible en: https://doi.org/10.1007/s12117-006-1017-4.

Jiménez- Villarejo Fernández, F. (2011). Novedades legislativas en materia de decomiso y de recuperación de activos. Revista de Derecho Penal, 34, 91-116.

Klip, A. (2009). European Criminal Law. An Integrative Approach. Antwerpen: Intersentia.

Maljević, A. (2011). "Participation in a criminal organization" and "conspiracy". Different legal models against criminal collectives. Berlín: Duncker und Humblot.

Manacorda, S. (2002). L'infraction d'organisation criminelle en Europe (Allemagne, Espagne, France, Italie, Union européenne). Paris: Presses Universitaires de France.

Marletta, A. (2016). Interinstitutional Relationship of European Bodies in the Fight against Crimes Affecting the EU's Financial Interests. Past Experience and Future Models. Eucrim. The European Criminal Law Associations' Forum, 3, 141 145.

Martin, J. M. y Romano, A. T. (1992). Multinational Crime. Terrorism, Espionage, Drug and Arms Trafficking. Thousand Oaks: Sage Publications.

Méndez Rodríguez, C. (2009). La lucha contra la delincuencia organizada: comentario a la Decisión marco 2008/841. Revista General de Derecho Europeo, 18, 6.

Mitsilegas, V. (2001). Defining organised crime in the European Union: the limits of European criminal law in an area of "freedom, security and justice". European Law Review, 26, 565-581.

- (2011). The Council Framework Decision on the Fight against Organized Crime: What can be done to strengthen EU legislation in the field? Bruselas: Parlamento Europeo, PE 453.195. Disponible en: http://www.europarl.europa.eu/studies.

Mitsilegas, V., Monar, J. y Rees, W. (2003). The European Union and Internal Security. Guardian of the People? Hampshire: Palgrave MacMillan. Disponible en: https://doi.org/10.1057/9780230504387.

Núñez Paz, M. Á. y Guillén López, G. (2009). El «arrepentido» en el ámbito del crimen organizado y en el tráfico de drogas. El artículo 376 del Código Penal español. Revista de Derecho de Extremadura, 5, 132-150.

Oficina de Naciones Unidas contra la Droga y el Delito (ONUDD). (2004). Guías legislativas para la aplicación de la Convención de las Naciones Unidas contra la delincuencia organizada transnacional y sus Protocolos. Nueva York: Naciones Unidas.

Parlamento Europeo. (2005). Informe sobre la propuesta de decisión marco del Consejo relativa a la lucha contra la delincuencia organizada, Comisión de Libertades Civiles, Justicia y Asuntos de Interior, A6-0277/2005, 28-9-2005.

Parlamento Europeo. (2006). Resolución legislativa del Parlamento Europeo sobre la propuesta de Decisión marco del Consejo relativa a la lucha contra la delincuencia organizada, 26-10-2005, DO C 272 E, de 9 de noviembre de 2006, p. 428. 
Parlamento Europeo. (2011). Resolución del Parlamento Europeo, de 25 de octubre de 2011, sobre la delincuencia organizada en la Unión Europea, DO C 131 E, de 8 de mayo de 2013, p. 66.

Parlamento Europeo. (2013). Informe del Parlamento Europeo, de 26 de septiembre de 2013, sobre la delincuencia organizada, la corrupción y el blanqueo de dinero: recomendaciones sobre las acciones o iniciativas que han de llevarse a cabo (Informe Iacolino), A7-0307/2013.

Parlamento Europeo. (2016). Resolución del Parlamento Europeo, de 25 de octubre de 2016, sobre la lucha contra la corrupción y el seguimiento de la Resolución de la Comisión CRIM [2015/2110(INI)].

Peers, P. (2011). EU Justice and Home Affairs Law (3a ed.). Oxford: Oxford University Press.

Roig Torres, M. (2016). La regulación del comiso. El modelo alemán y la reciente reforma española. Estudios Penales y Criminológicos, 36, 199-27.

Ruggeri, S. (2015). Transnational Evidence and Multicultural Inquiries in Europe. Developments in EU Legislation and New Challenges for Human Rights-Oriented Criminal Investigations in Cross-border Cases. Heidelberg: Springer.

Ruiz Díaz, L. J. (2015). La lucha contra el crimen organizado en la Unión Europea. Aspectos internos y dinámicas externas del discurso securitario [tesis doctoral]. Univesidad de Granada. Disponible en: https://bit.ly/2O56cZx.

Scherrer, A., Mégie, A. y Mitsilegas, V. (2009). The EU role in fighting transnational organized crime. Bruselas: Parlamento Europeo, PE 410.678. Disponible en: http://www.europarl.europa.eu/studies.

Siclari, D. (2016). The New Anti-Money Laundering Law. First Perspectives on the 4th European Union Directive. London: Palgrave Macmillan.

Sousa Santos, B. (2010). The European Arrest Warrant in Law and in Practice: A Comparative Study for the Consolidation of the European Law-Enforcement Area. Disponible en: https://bit.ly/2NkOP1B. 